\title{
Bilateral Scrotal Flaps: A Novel Ideain the Management of Massive Scrotal Lymphoedema
}

\author{
Nangole Wanjala Ferdinand, Biribwa Kansiime Peter \\ Department of Surgery, University of Nairobi, Nairobi, Kenya \\ Email address: \\ nangole2212@gmail.com (N. W. Ferdinand) \\ To cite this article: \\ Nangole Wanjala Ferdinand, Biribwa Kansiime Peter. Bilateral Scrotal Flaps: A Novel Ideain the Management of Massive Scrotal \\ Lymphoedema. Journal of Surgery. Vol. 6, No. 4, 2018, pp. 92-96. doi: 10.11648/j.js.20180604.13
}

Received: May 7, 2018; Accepted: May 29, 2018; Published: July 16, 2018

\begin{abstract}
Massive Scrotal lymphoedema is a debilitating condition that could result in both psychological and physical trauma to the patient. Irrespective of the cause of this condition, surgery remains the cornerstone in its management. A variety of surgical procedures have been described with varied degree of success. A total of eight patients with massive scrotal lymphoedema of ages between 15 and 60 years were managed by the authors. The mean excision of the scrotal tissue was 5.7 kilogrammes. All patients had post excision defect reconstructed with bilateral scrotal flaps. No skin grafts were utilized in any patient. They all healed well without any complications and were able to resume to their normal functions within nine weeks. No recurrence was noted at two years of follow up. Bilateral scrotal flap is an effective method of managing massive scrotally mphoedema. It allows for massive removal of scrotal tissue and primary repair of the defect using scrotal tissue that allows for early return to work and sexual activities. The complications are minimal and there is high patient satisfaction.
\end{abstract}

Keywords: Scrotal Lymphoedema, Reconstruction, Flaps

\section{Introduction}

Scrotal lymphoedema is a relatively uncommon problem. The incidence of the condition in our set up is not known. Among the aetiological factors include congenital causes, filiariasis, tuberculosis, hidradenitis suppurativa and malignancies [1-4], Patients with massive lymphoedema are unable to ambulate well and may be forced to abandon their normal lifestyles including dropping out of school. Patients who are sexually active may be forced to withhold from any sexual activities due to physical barrier and discomfort caused by the enlarged scrotum and buried penis.

The management of this condition is both medical and surgical. Medical management is targeted in patients whose lymphoedemais of a known aetiology. It is however only effective in early cases and rarely successful in well established cases. Other than treatment compression therapy has also been advocated [5]. Surgical management on the other hand addresses the huge scrotal and penile tissues that prevent patients from engaging in their normal activities. The surgical options include massive excision of the redundant scrotal and penile tissues and reconstruction with split thickness skin graft $[1,6]$. Other options include excision of the redundant tissue and reconstruction of the defects with perineal, or fasciocutaneous flaps [7-9].

Use of scrotal flaps allows for the reconstruction of the scrotum with tissues that have cremasteric muscle that allows for thermoregulation of the testicular temperatures that is critical for spermatogenesis. Scrotal tissue is thin, pliable and relatively mobile making it easier to cover the penis while allowing for easier movement during intercourse. The tissue doesn't have subcutaneous fat associated with other local flaps and is thus less bulky. We present our experience in the use of the bilateral scrotal flaps in the management of massive scrotal lymphoedema.

\section{Materials and Methods}

Patients with massive scrotal lymphoedema were seen by the authors between January2009 and December 2016. A thorough physical examination was done to determine the cause of scrotal swelling. Investigations done included haemogram, urea, electrolytes and creatinine levels. Specific investigations included blood smear for microfilariasis. Radiological investigation done was scrotal ultrasounds and micturatingcystourethrogram in patients who had urinary 
symptoms. Consent was then taken and patients prepared for surgery. After surgery all patients were managed in the ward for a minimum of one week. While in the ward they were assessed for early complications including wound sepsis, hematoma, seromaand flap necrosis. Upon discharge they were followed up in the plastic clinic for a minimum of 2 years. The reviews were at a weekly interval for the first one month followed by a monthly interval for the next three months after which they were seen at every three months for the remaining duration. During reviews they were assessed for lymphedema recurrence, ability to return back to their normal lifestyle esandsexual activities.

\subsection{Surgical Technique}

Surgery was done under general anesthesia. Patients were positioned in supine position with legs abducted on the operating table. Cleaning of the scrotum, perineum, upper thighs and lower abdomen was done with povidone iodine solution. Urethral catheterization was then performed in all patients with a Foleys catheter. The flaps were then marked in the posterior lateral aspect of the scrotum. (figure 1,2).

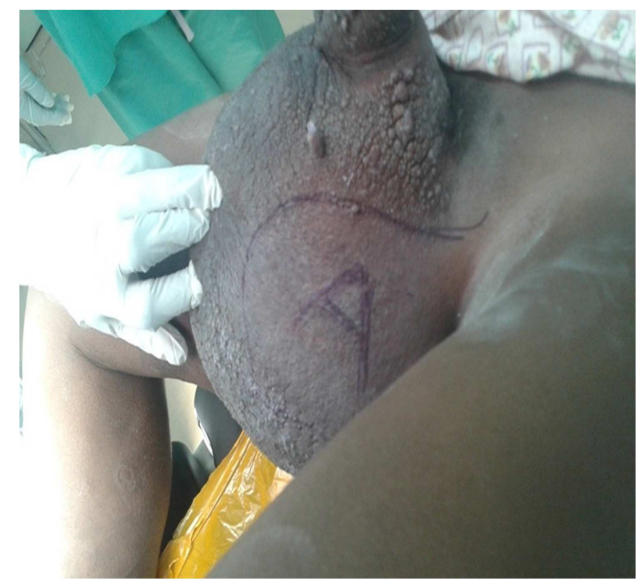

Figure 1. Demonstrates the posterolateral scrotal skin that will be utilized in making the flaps marked $A$.

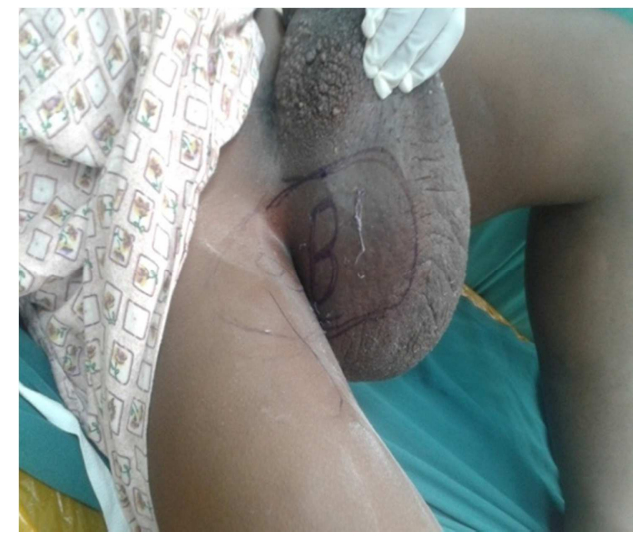

Figure 2. Demonstrates the posterolateral scrotal skin that will be utilized in making the flaps marked $B$. Note the relatively normal skin in the posterior lateral aspect of the scrotum. The two flaps marked $A$ and $B$ that will be utilized in covering the scrotum and the penis(figure 6).

Lidocaine with adrenaline 1:100000 was infiltrated along the marked incision line. With the aid of cautery the massive scrotal and penile tissues were excised. (figure 3, 4).

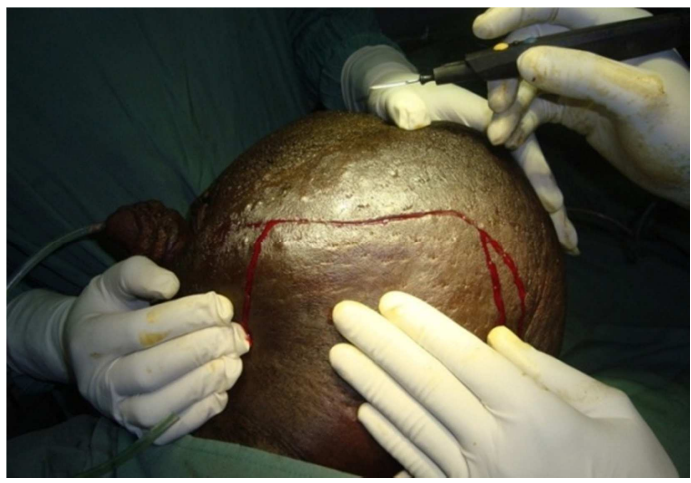

Figure 3. Posterolateral flap being raised in one of the patients after infiltration with dilute adrenaline salina and Lidocaine solution.

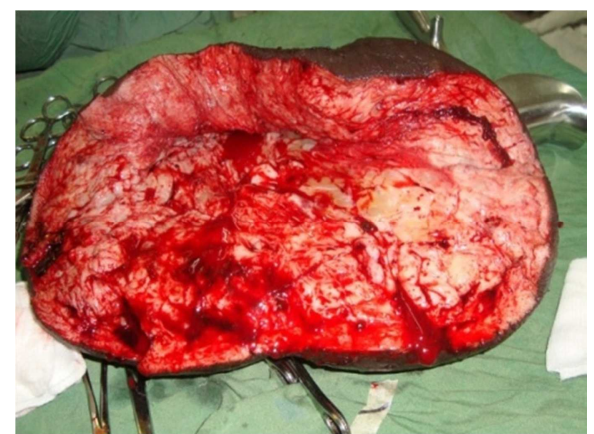

Figure 4. Excised scrotal and penile tissue, weight 5040 grams.

After excision of the redundant tissues, fashioning of the flaps were done (Figure 5).

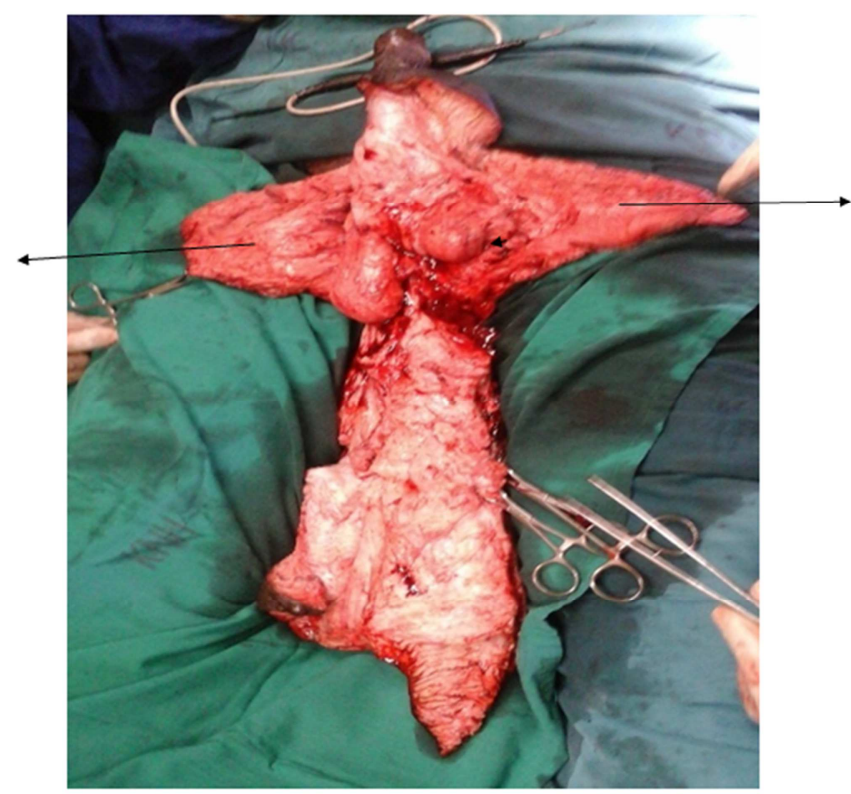

Figure 5. Posterolateral scrotal flaps indicated with arrows.

The flap was raised in the subcutaneous plane above the colles fascia. Two flaps one from either side of the scrotum were fashioned. One flap was utilized to wrap around the penis and suturedon the preputial inner skin. The other flap 
was fashioned and utilized in reconstructing the scrotum. (figure 6)

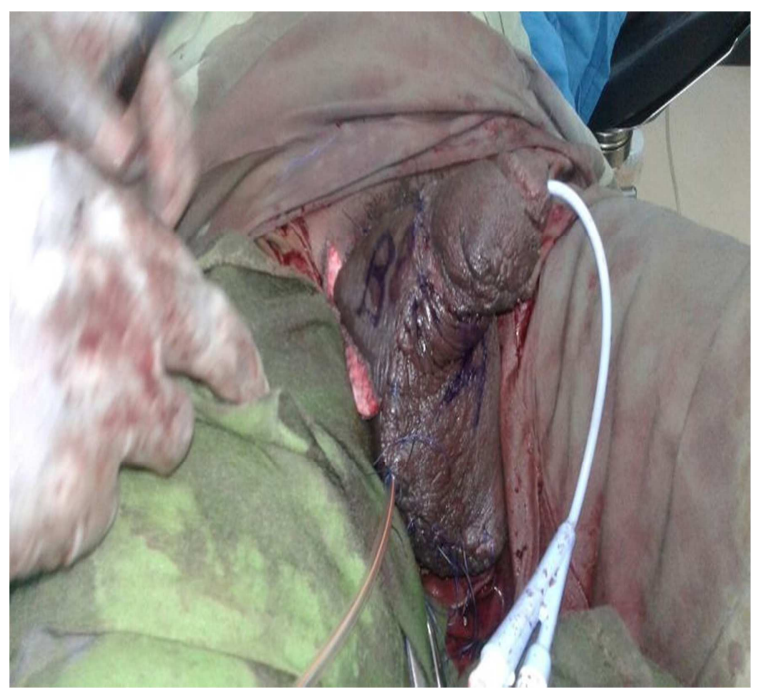

Figure 6. Posterolateral flaps used to reconstruct the scrotumA, and penile shaft $B$.

A drain was then inserted in the newly reconstructed scrotum and kept in place until it was inactive. Wounds were dressed with bactrigras and gauze dressings. Perioperative monitoring of the patients and the flaps were done. Change of dressings was done on the third postoperative day and repeated every after two to three days until the wounds healed. Postoperative complications were noted. Patients were reviewed in the clinic at regular intervals till 2 years. (Figures 7, 8, 9, 10)

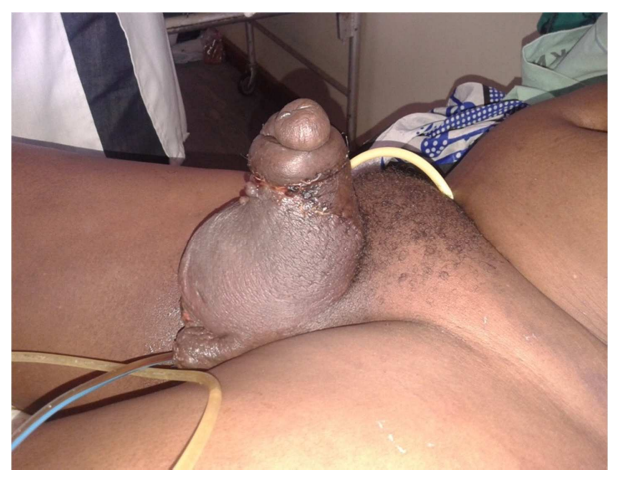

Figure 7. Patient at one week post surgery, Arrows shows, left scrotal flap utlilised to reconstruct the scrotal sac. Right scrotal flap utilized to cover the penile shaft.

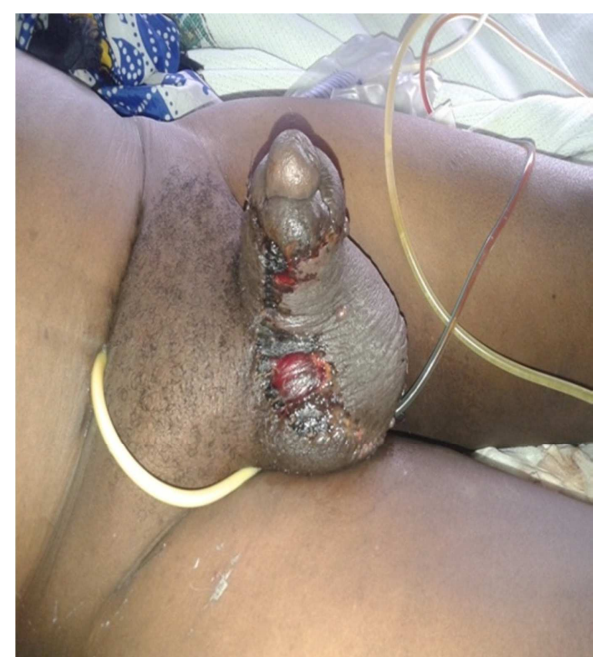

Figure 8. Note partial distalflap necrosis in one of the patients; healed with conservstive management.

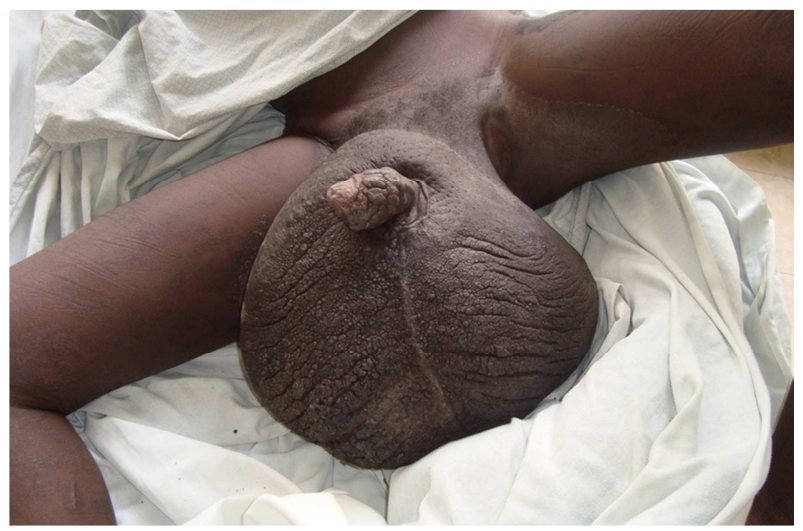

Figure 9. Patient with massive scrotal lymphoedema, before surgery , at one month of follw up after surgery (figure 10).

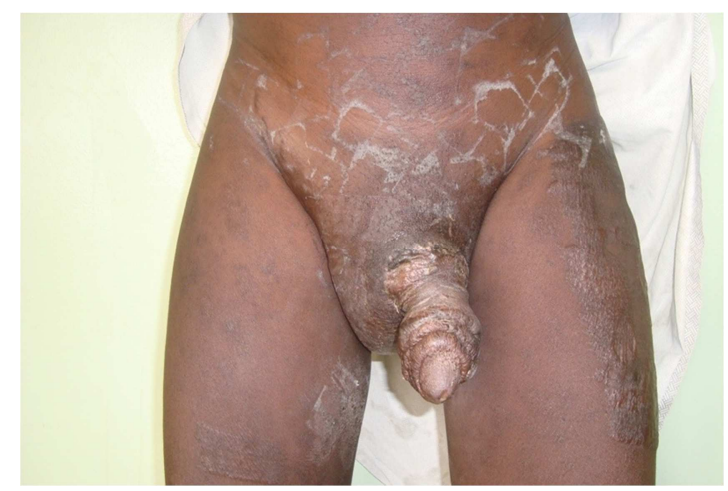

Figure 10. Patient at one months after surgery. 


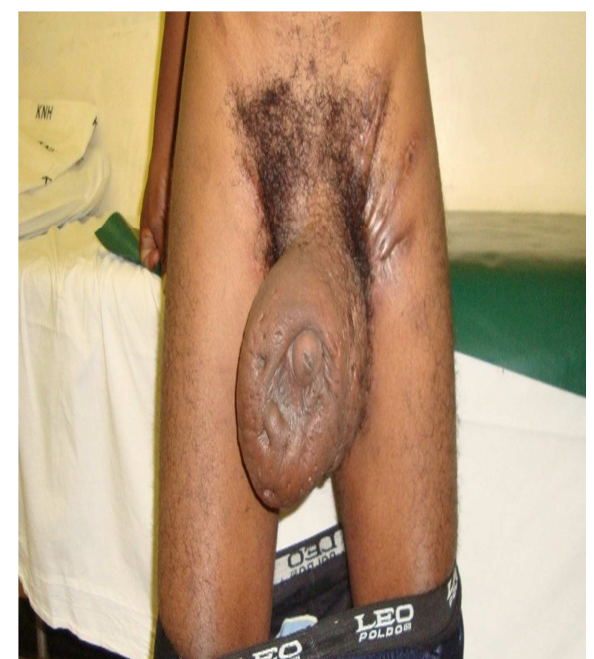

Figure 11. Patient before surgery and at one year of follw up after surgery (figure 12).

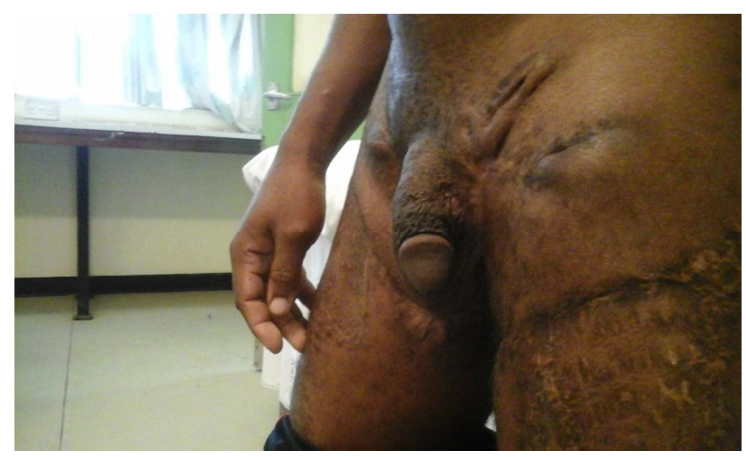

Figure 12. Patient with scrotal lymphoedema before and 2 years after surgery.

\section{Results}

A total of eight patients were seen by the authors with massive scrotal lymphoedema between 2009 and 2016. The patients were aged 15, 19, 30, 34, 38, 39, 43 and 56 years of age. One patient had lymphoedema secondary to hidradenitis suppurativa, two patients had congenital scrotal lymphoedemawhile the remaining patients the cause of lymphedema couldn't be established. One patient had urethra stricture necessitating suprapubic catheterization. All patients had their blood smears negative for filariasis; Radiological investigations for hydrocele were all negative.

The mean peniscrotal tissue resected during surgery was 5,700 grams (figure 3) with a range of 1050 grams to 7300 grams. Bilateral posterior lateral scrotal flaps were utilized to cover the penis and the scrotum in all patients. No skin grafts or other flaps were utilized in covering the wounds. Post operatively no haematoma nor infection was noted in any patient. One patient had distal flap necrosis. (figure 8). The wound however healed with conservative management. Six out of the eight patients who were sexually active were able to resume to their sexual lifestyle within six weeks of surgery; the range being 3 weeks to 6 weeks. Complete recovery from surgery and ability to return to work/school was 9 weeks; range being 6 weeks to 13 weeks. There was no recurrence of lymphoedemaat two years of follow up in any of the patients.

\section{Discussion}

Scrotal lymphoedema is due to accumulation of the lymphatic fluid in the scrotum. The lymph causes an intense inflammatory reaction resulting in cellular hyperplasia, fibrosis and eventually hypertrophy of the subcutaneous tissues. As a result of this there is marked deformity of the penis and the scrotum resulting in complete disfigurement of the genitalia. However, in most cases as demonstrated in our series, the tissues in the posterior and lateral aspect of the scrotum seem to be minimally involved and more less remains normal (figure 1 and 2). This could be due to the alternative lymphatics that drain with the internal iliac veins through the ischiorectal fossa. These tissues are thus available for reconstruction with minimal risk of recurrence as experienced in all our patients.

Scrotal skin, unlike skin in any other part of the body has cremasteric muscle. This muscle is thermo sensitive, assisting in regulation of testicular temperatures. The skin also has minimal fat tissues and hence ensures in keeping the testis at lower temperatures than the rest of the body. It is thus the best tissue to cover the testis and should always be used when available.

Scrotal flaps in the management of massive scrotal lymphoedema has been reported in literature by several authors Singh V et alin series of 48 patients spanninga decade reported the use of the posterior or lateral scrotal skin in reconstruction of the patients with massive scrotal lymphedema [1]. Champaneria M C et al also reports the use of the posterior based scrotal flap in a patient with massive peniscrotal lymphoedema. [8] In both cases however these flaps were utilized together with the skin grafts to cover the penile defect.

Bilateral scrotal flaps allows for maximum utilization of 'normal' scrotal tissue to cover the defects of the scrotum and the penis. While designing the flaps one should recruit as much normal scrotal skin as possible. This would allow forone to trim and discard the extra skin during the insertion of the flaps. The massive weight of the scrotum applies traction on the posterior lateral tissue that results in traction related hypertrophy that in return results in increased vascularity akin to tissue expansion. The net result is highly vascuralised tissue that results in reliable flaps. (All flaps though random survived except for one which had partial tip necrosis.) Initially the flaps may appear bulk but in our experience the tissues quickly resolve as the hypertrophy wears off. In majority of the cases the scrotal and penile sizes returned to near normal by the end of the third month. (Figure 3). The aesthetic appearance of the penis and the scrotum in all the cases was satisfactory to the patients. (figure 9, 10). There were also no complains of pain nor discomfort during sexual intercourse for patients who were sexually active.

Skin graft is one of the techniques that iswidelyused in the 
reconstruction of the scrotum and the penis in patients with massive scrotal lymphedema [1-3]. It is probably the commonest used technique and has been widely quoted in literature. The advantages of the skin graft are that it is readily available and easy to perform. The disadvantages however include poorgraft take and donor site morbidity. The graft may also contract resulting in peyronie like deformity of the penis with poor aesthetic outcomes. There is also reduction in the girth of the penis that maybe of concern to the patient. Due to the shear during sexual intercourse the graft may tear resulting in wounds that may impair normal sexual activities.

Other commonly used methods include fasciocutaneous flap from the groin and the iliac region [9-13]. These flaps are however bulk. They are aesthetically unappealing and may need several revisions. They are also devoid of thermoregulatory functions for proper spermatogenesis. They should thus be limited in cases where neither scrotal flaps nor skin grafts are possible. The role of lymph node transplant surgery in lower limb lymphoedema has now been well documented [14] It is not yet clearwhether the same benefits may be noted in giant scrotal lymphedema.

\section{Conclusion}

Bilateral scrotal flaps provide a viable alternative in the reconstruction of the penile shaft and scrotum in patients with massive peniscrotal lymphoedema. The technique is easy and is associated with few complications. It allows for quick return to work and sexual functions. It also provides an ideal environment for spermatogenesis. The aesthetic results are good and there is minimal chance of recurrence.

See comment in PubMed Commons below.

\section{References}

[1] Singh V, Sinha RJ, Sankhwar SN et al Reconstructive surgery for penoscrotal filarial lymphedema: a decade of experience and follow-up. Urology. 2011;77(5):1228-31. http://dx.doi.org+/10. 10+ 16/j.urology.2 010.10.026. PMid: [PubMed].

[2] Al-Shaham AA, Sood S. Recurrent furunculos is as a cause of isolated penile lymphedema: a case report. J Med Case Reports. 2010;4(1):196. http://dx.doi.org/10.1186/1752-19474-196. PMid: [PMC free article][PubMed].
[3] ThejeswiP, Prabhu S, Augustine AJ et al Giant scrotal lymphoedema: a case report. Int J Surg Case Rep. 2012;3(7):269-71.

http://dx.doi.org/10.1016/j.ijscr.2012.03.005. PMid: [PMC free article][PubMed8].

[4] Reitsma W, Wiegman MJ, Damstra RJ. Penile and scrotal lymphedema as an unusual presentation of Crohn's disease: case report and review of the literature. Lymphology. 2012;5(1):37-41. PMid: [PubMed] 2. Godoy JMP, Facio FN Jr.

[5] Carvalho ECM et al. New compression mechanism in penilescrotal lymphedema and sexual rehabilitation.Urol Ann. 2014;6(1):88-90. http://dx.doi.org/10.4103/09747796.127025. PMid: [PMC free article][PubMed].

[6] Miquel Modolin, Anuar Ibrahim; Surgical treatment of lymphoedema of the penisand scrotum. linics; 2006;AugVol 61.04 Sao Paulo

[7] Halperin TJ1, Slavin SA, Olumi AF, Borud LJ. Surgical management of scrotal lymphedema using local flapsJ PlastReconstrAesthetSurg.2013 Feb; 66(2):281-6. doi: 10.1016/j.bjps.2012.06.024. Epub 2012 Aug 4.

[8] Champaneria MC1, Workman A et al.Reconstruction of massive localized lymphoedema of the scrotum with a novel fasciocutaneous flap: A rare case presentation and a review of the literatureJ Plast ReconstrAesthet Surg. 2014 Dec; 67(12):1719-25. doi: 10.1016/j.bjps.2014.07.031. Epub 2014 Aug 5 .

[9] Pastor C, Granick MS. Scrotal lymphedema. Eplasty. 2011;11:ic15. PMid: [PMC free article][PubMed].

[10] Parmar HD. The surgical approach in huge scrotal lymphedema.Int J Med Sci Public Health. 2013;2(1):153-5. http://dx.doi.org/10.5455/ijmsph.2013.2.153-155

[11] Machol JA 4th, Langenstroer P, Sanger JR. Surgical reduction of scrotal massive localized lymphedema (MLL) in obesity. J Plast Reconstr Aesthet Surg. 2014; 67(12):1719-25.

[12] Franklin Vivesa, Herney Andrés García-Perdomo, b, c, Ginna Marcela Ocampo-Flórez Giant lymphedema of the penis and scrotum: a case report. Autops Case Rep. 2016 Jan-Mar; 6(1): $57-61$.

[13] Parmar HD. The surgical approach in huge scrotal lymphedema. Int J Med SciPublic Health. 2013;2(1):153-5.

[14] Sapountzis S, Ciudad P, Lim SY, et al. Modified Charles procedure and lymph node flap transfer for advanced lower extremity lymphedema. Microsurgery. 2014;34(6):439-47. http://dx.doi.org/10.1002/micr.22235. PMid: [PubMed]. 